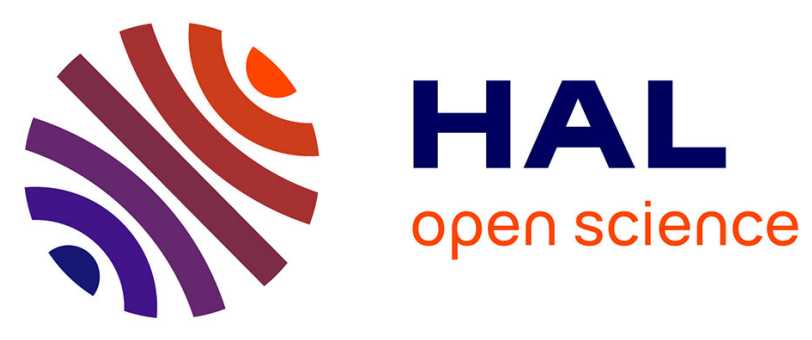

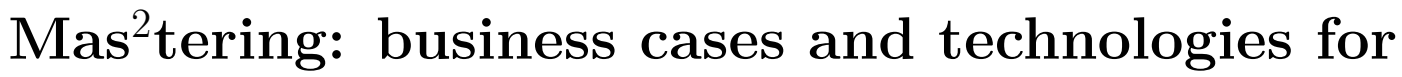 low-voltage flexibility aggregation with prosumers and local energy communities Workshop
}

Thomas Messervey, Mario Sisinni, Juan Manuel Espeche, Zia Lennard, Meritxell Vinyals, Marie-France Robbe, James Sharman, Julien Ardois

\section{To cite this version:}

Thomas Messervey, Mario Sisinni, Juan Manuel Espeche, Zia Lennard, Meritxell Vinyals, et al.. Mas ${ }^{2}$ tering: business cases and technologies for low-voltage flexibility aggregation with prosumers and local energy communities Workshop. Proceedings, 2017, Special Issue "Selected Papers from Sustainable Places 2017 (SP2017) Conference", 1 (7), pp.1103. 10.3390/proceedings1071103 . cea03086568

\section{HAL Id: cea-03086568 https://hal-cea.archives-ouvertes.fr/cea-03086568}

Submitted on 22 Dec 2020

HAL is a multi-disciplinary open access archive for the deposit and dissemination of scientific research documents, whether they are published or not. The documents may come from teaching and research institutions in France or abroad, or from public or private research centers.
L'archive ouverte pluridisciplinaire HAL, est destinée au dépôt et à la diffusion de documents scientifiques de niveau recherche, publiés ou non, émanant des établissements d'enseignement et de recherche français ou étrangers, des laboratoires publics ou privés. 


\title{
Mas'tering: Business Cases and Technologies for Low-Voltage Flexibility Aggregation with Prosumers and Local Energy Communities Workshop ${ }^{+}$
}

\author{
Thomas Messervey ${ }^{1}$, Mario Sisinni ${ }^{1}$, Juan Manuel Espeche ${ }^{1}$, Zia Lennard ${ }^{1, *}$, Meritxell Vinyals ${ }^{2}$, \\ Marie-France Robbe ${ }^{2}$, James Sharman ${ }^{3}$ and Julien Ardois ${ }^{4}$ \\ 1 R2M Solution, s.r.l., Via Fratelli Cuzio 42, 27100 Pavia, Italy; thomas.messervey@r2msolution.com (T.M.); \\ mario.sisinni@r2msolution.com (M.S.); juan.espeche@r2msolution.com (J.M.E.) \\ 2 Commissariat à l'énergie atomique (CEA), Institut LIST, Université Paris-Saclay, F-91120 Palaiseau, France; \\ meritxell.vinyals@cea.fr (M.V.); marie-france.robbe@cea.fr (M.-F.R.) \\ 3 SMS-Plc, Ltd., Cardiff Gate Business Park, Prennau House, Copse Walk, Pontprennau, Cardiff CF23 8XH, \\ UK; james.sharman@sms-plc.com \\ 4 Engie Lab Crigen, 361 Ave. du Président Wilson, 93210 Saint-Denis, France; julien.ardeois@engie.com \\ * Correspondence: zia.lennard@r2msolution.com; Tel.: +39-382-172-6596 \\ + Presented at the Sustainable Places 2017 (SP2017) Conference, Middlesbrough, UK, 28-30 June 2017.
}

Published: 9 November 2017

\begin{abstract}
This report summarises the conduct and key findings from the fourth and final scientific workshop organised under the Mas'tering project (Multi-Agent Systems and Secured coupling of Telecom and Energy gRIds for Next Generation smart grid services), which is co-funded by the European Union under the FP7 programme. The workshop was co-located with Sustainable Places 2017 hosted by Teesside University in Middlesbrough, UK. Sustainable Places is an annual international conference focused on innovations for Energy-efficient Buildings and the wider smart grids that connect them. This fourth edition of the Mas'tering workshop series aimed at validating the project's work to date with respect to its approach, technologies, use cases and in-progress results. For this purpose, a panel of three experts was formed and to them the project presented an Overview \& Approach, Physical Testing at the ENGIE Crigen facilities, simulation of the Cardiff Grid, Project Use Cases and the Business Model Approach. Thematic issues and conclusions from the presentations and discussions are provided herein.
\end{abstract}

Keywords: flexibility management; local flexibility aggregator; social housing; physical testing at Engie Lab Crigen; simulation of the Cardiff grid; local energy communities; DSO; retailer; telecom

\section{Introduction}

In this fourth edition of the Mas'tering Workshop, focus was placed on validating project results to include targeted market points of entry represented by smart grid solution providers, existing aggregators, and social housing operators. For this reason, a "Mas²tering only" workshop was designed as opposed to previous editions in which clustering activities took place with similar projects or in which thematic experts also offered presentations related to their areas of expertise.

\section{Presentations Delivered}

Project storyline: Each pillar was described and related to how it fits into the overall Mas²tering solution. One area of emphasis was discussion on the three levels of optimisation which take the shape of Use Cases (UC1-3) and form the logic behind how the Mastering solution is implemented. In brief, those three levels are described below and illustrated in Figure 1: 
- Level One (UC1) - The Customer Energy Management System (CEMS) agent carries out an inhome optimisation behind the meter intended to minimise the prosumer's energy bill by selfconsuming, Time-of-Use (ToU) optimisation, and by controlling the maximum load.

- Level Two (UC2) - The Aggregator (AGR) agent enables a local flexibility market among the Prosumers, members of its portfolio (via corresponding CEMS agent) intended to collectively optimise energy flows within the community.

- Level Three (UC3) - The DSO agent establishes negotiations for procuring flexibility from AGRs intended to perform grid congestion management and support grid reinforcement savings through flexibility trading agreements.

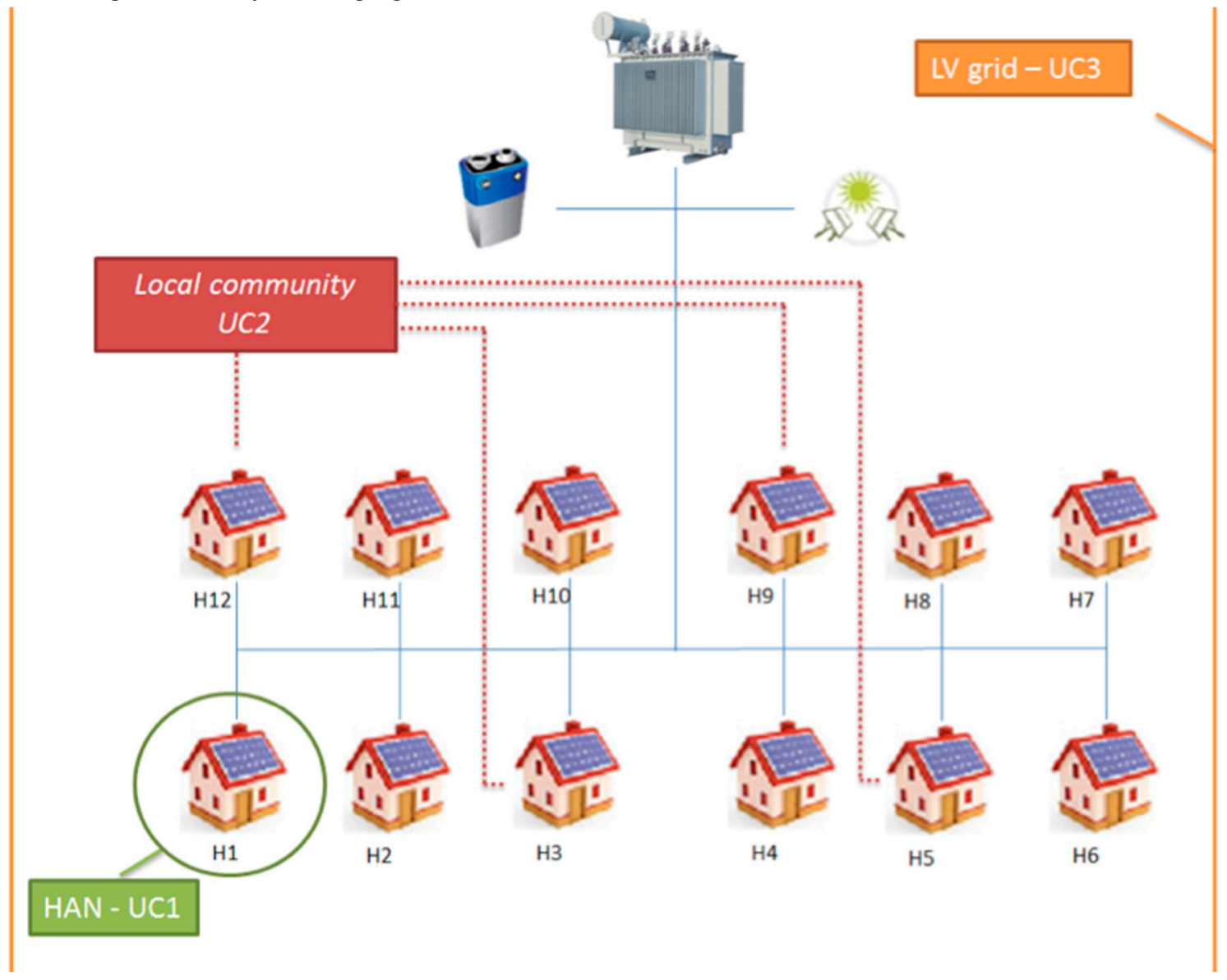

Figure 1. Mas²tering project storyline illustrating three use cases (UC1-3).

Physical testing: ENGIE experimental facilities include one experimental building equipped with a flexible load bench (emulating use of electrical heaters) and two houses already equipped with a flexible load bench (up to $5.2 \mathrm{~kW}), 12 \mathrm{kWe}$ of PV, storage system $(7 \mathrm{kWh})$, one EV and related charging station and existing energy management systems able to monitor and/or manage individually this equipment. The building and two houses form a local grid, which is a basic representation of local communities of prosumers targeted in Mas²tering.

Simulation-based demonstration activities using the Pontypool, Cardiff, UK, electrical grid data to validate the MAS Platform on a larger scale than what is possible at the ENGIE Labs for physical testing. The first part of the presentation was dedicated to the description of the simulation environment and to the activities performed to define reliable and representatives smart grid scenarios. The targeted area for simulation is a portion of LV grid supplied by a single $500 \mathrm{kVA}$ transformer and comprising 184 residential users. Based on the input data provided by the local Distribution System Operator (Western Power Distribution, Bristol, UK), the project's activities have led to the definition of 12 different smart grid scenarios, each characterised by a different penetration of smart technologies and home appliances. Then, for each scenario, each prosumer of the reference grid has been characterised in terms of: allocation of smart technologies, allocation of deferrable loads 
and allocation of interruptible loads. Moreover, further classifications include the definition of appliances cycles, categorisation of prosumers (to emulate their behaviour), definition of typical shifting intervals, creation of Photovoltaic generation profiles and definition of Time-of-Use tariffs. Considering the granularity of input data (daily consumption profiles for 15 typical days of the year), the combination of all variables led to the conduction of almost 10,000 optimisations.

Business Model Opportunities: One area where panel feedback was requested involved the evolution of the flexibility management market across time from a non-functional (today) to a fully functional (future) flexibility market where the intermediate stage (near future) consists of various players prototyping niche market solutions for various business cases.

Energy Markets \& Independent Aggregators in the UK SMS-PLC is currently investigating new business models to expand its UK based asset-ownership portfolio. One of the most intriguing opportunities leverages the desire for independent and supplier led aggregators to expand their generation and storage portfolios and matches this with the expertise of SMS to collect and analyse data, carry out consultancy services to identify suitable assets and provide a viable asset ownership mechanism. In this capacity, SMS has had the opportunity to interview several aggregators with respect to their current operations and business models and also with respect to their views on the Mastering approach and views on residential flexibility. Given the nature and timeliness of these discussions with respect to the workshop, it was decided to dedicate part of the workshop and presentations to the views exchanged in these interviews. The interviewed aggregator organisations were also invited to and solicited for participation in the workshop. Unfortunately, none accepted despite relative proximity to the event itself. The rationale was competing priorities coupled with a position on the topic that it is still too far in the future and carries too much risk to actively engage/commit resources to residential flexibility, which is perceived to be too complex to unlock and be of little economic value. They were happy to be kept informed of project progress in the area but politely declined active participation for the time being. During the workshop, the intent was to share these experiences and see if the panel members had similar occurrences in their work.

\section{Key Findings and Discussion}

A series of prepared questions and open discussion shaped the panel session. The following paragraphs capture the main topic areas and points of interest.

Decentralised Decision Making: The panel was in agreement with the approach of decentralised decision making (MAS) coupled to a bottom-up prosumer centric approach and leveraging local energy communities. It was noted that participant "buy-in" to pilot programs was often not linked to the concept of flexibility management but benefits involved in the retrofit program (in the cited case, new kitchens with smart appliances as part of a larger home retrofit).

Validation of the Simulation Approach: The attendees appreciated the approach used for the simulation activities. In particular the definition of numerous smart grid scenarios based on expected evolution trends appeared much more reliable than the creation from scratch of a scenario where all Mastering objectives could be achieved. A positive feedback was also given to the KPIs defined as part of the validation plan.

Social Housing as a Market Point of Entry: All attendees recognised the recent increased interest of energy stakeholders in demand response and flexibility management services, especially when combined with new concepts such as blockchain technology. Social housing districts show some advantages with respect to traditional residential areas in terms of Demand Response readiness. These districts are often made of very similar houses, all equipped with the same set of appliances. It is important to note that tenants do not generally own the houses and their assets, nor have the possibility to choose their energy supplier or local distributor, which is generally chosen by a municipality and is unique. This limitation on the consumers' side can greatly support DSO or local actors in the local management of flexibility.

Standards, Market Evolution and Market Models: The panel had no problem with the presented Mastering view of market evolution (e.g., aggregators targeting niche markets via local energy communities and suppliers offering bundled services in the near to mid-term (pockets of activity) 
and partnerships forming in the long-term to achieve scalability. However, it was remarked that it is still very early and what is really needed is serious "true European and worldwide" work in the standards area similar to what happened in the telco community 10-20 years ago with the formation of the 3rd Generation Partnership Project (3GPP) which united seven telecommunication standards development organisations to provide a stable environment in which to develop cellular telecommunication network technologies. It was acknowledged that there is important ongoing work in the smart grid area and that Universal Smart Energy Framework (USEF) in particular was a promising model but that the community at large has not come together as convincingly as Telcos did under 3GPP and that a stable platform may still be lacking.

Business model reproducibility and Scalability: There may be a gap between providing consumer choice/consumer centricity and the ability to achieve scalability and meaningful implementation of business models-especially when there are so many permutations of local energy community characteristics (governance and technologies) and inquired how we are planning to get around that. This reinforced the need for standards work to bring a massive number of vendors and market participants around the table. In the interim, it is indeed the case to work on niche market applications (with reference to segments of social housing) and that typically, one needs to approach flexibility management services in a creative way by offering something else (energy improving retrofitting hardware and monitoring services) and attaching flexibility management concepts to that.

Costs to Prosumers: The panel asked for the costs related to the Energy Box and SaaS solutions. It was pointed out that costs to prosumers (energy box) were likely to be subsidised or bundled within other services and that the cost of the MAS aggregation platform (utilised by the local flexibility aggregator) would depend at least in the near term on the value proposition made possible to that specific aggregator which is likely to be tied to the size of their portfolio and amount of flexibility under management. Equally important are the bundled services or other benefits (client retention) made possible. As a result, there will be a period of market positioning and case by case value proposition design and business model development on a client by client basis.

Consideration of Small Commercial: In the US there are currently no flexibility aggregators for small commercial businesses to trade or commoditize on their flexibility, and the fact that the MAS Platform is theoretically able to serve such an end-user base makes it interesting for widespread market adoption. This is now becoming an area activity at Berkeley Energy and Climate Institute (BECI) and the project "XBOS-DR: An Extensible Building Operating System for Demand Response" [1] was mentioned as one conducted research for this market segment via the development of a low-cost microelectromechanical system (MEMS)-based ultrasonic anemometer to improve building performance and a demand-response enabling platform for small and large commercial buildings. Dynamic tariff structures and demand charges were also highlighted as important parameters in constructing viable business models and differences between US and EU energy pricing were discussed.

\section{Conclusions}

The workshop was specific to the Mas²tering project, brought together 25-30 participants and used an expert panel approach and questionnaire to provide validation of project results as they related to technologies, the use cases, project demonstration and simulation activities and the business cases. Presentations from the workshop and also the preceding ones are available at http://www.mas2tering.eu/workshops/.

Acknowledgments: Mas²tering (Multi-Agent Systems and Secured coupling of Telecom and Energy gRIds for Next Generation smart grid services) is co-funded by the European Union under the FP7 programme, grant $n^{\circ}$ 619682. The Mas²tering project can be referenced at http://www.mas2tering.eu/.

Author Contributions: Paper written by Thomas Messervey, Zia Lennard, Juan Manuel Espeche, and Mario Sisinni. Reviewed by Marie-France Robbe, Meritxell Vinyals, Julien Ardois, and James Sharman.

Conflicts of Interest: The authors declare no conflict of interest. 


\section{References}

1. Berkeley Energy and Climate Institute-Project List. Available online: http://bets.cs.berkeley.edu/projects/ (accessed on 27 October 2017).

(C) 2017 by the authors. Licensee MDPI, Basel, Switzerland. This article is an open access article distributed under the terms and conditions of the Creative Commons Attribution (CC BY) license (http://creativecommons.org/licenses/by/4.0/). 